\title{
Associations of home food availability, dietary intake, screen time and physical activity with BMI in young American-Indian children
}

\author{
Chrisa Arcan ${ }^{1, *}$, Peter J Hannan ${ }^{1}$, Jayne A Fulkerson ${ }^{2}$, John H Himes ${ }^{1}$, \\ Bonnie Holy Rock ${ }^{1}$, Mary Smyth ${ }^{1}$ and Mary Story ${ }^{1}$ \\ 'Division of Epidemiology and Community of Health, School of Public Health, University of Minnesota, 1300 \\ South 2nd Street, Suite 300, Minneapolis, MN 55454, USA: ${ }^{2}$ School of Nursing, University of Minnesota, \\ Minneapolis, MN, USA
}

Submitted 29 March 2011: Accepted 10 January 2012: First published online 29 February 2012

\begin{abstract}
Objective: To evaluate associations between home environmental factors and BMI of young American-Indian children.

Design: Cross-sectional and prospective study.

Setting: School-based obesity prevention trial (Bright Start) on a Northern Plains Indian reservation in South Dakota. Mixed model multivariable analysis was used to examine associations between child BMI categories (normal, overweight and obese) and home food availability, children's dietary intake and physical activity. Analyses were adjusted for age, gender, socio-economic status, parent BMI and school; prospective analyses also adjusted for study condition and baseline predictor and outcome variables.

Subjects: Kindergarten children ( $n$ 424, $51 \%$ male; mean age $=5 \cdot 8$ years, $30 \%$ overweight/obese) and parents/caregivers ( $89 \%$ female; $86 \%$ overweight/obese) had their height and weight measured and parents/caregivers completed surveys on home environmental factors (baseline and 2 years later).

Results: Higher fast-food intake and parent-perceived barriers to physical activity were marginally associated with higher probabilities of a child being overweight and obese. Vegetable availability was marginally associated with lower probabilities of being overweight and obese. The associations between home environmental factors and child weight status at follow-up were not significant.

Conclusions: Findings indicate that selected aspects of the home environment are associated with weight status of American-Indian children. Obesity interventions with this population should consider helping parents to engage and model healthful behaviours and to increase availability of healthful foods at home.
\end{abstract}

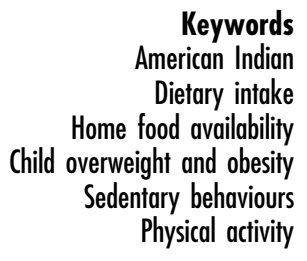

Overweight and obesity are serious public health issues among children in the USA and disproportionately impact minority youth ${ }^{(1,2)}$. Although national data are not available for American-Indian children living on reservations, a study with roughly 11000 American-Indian schoolchildren found that $40 \%$ of 5 -year-olds were overweight/obese ${ }^{(3)}$. Based on data of low-income pre-school children from the Early Childhood Longitudinal Study Birth Cohort, 4-year-old American-Indian children had the highest prevalence of obesity $(31 \cdot 2 \%)$ and exceeded that of each other racial $\operatorname{group}^{(4,5)}$.

Environments such as home, school and community interplay in the development of overweight or obesity ${ }^{(6)}$. The home environment, including parental weight status and family behaviours around food and physical activity, are influential, especially during early childhood $^{(7)}$.
However, studies examining associations between home food availability or restaurant meal consumption among children, including American Indians, have found no associations with children's BMI ${ }^{(8,9)}$. There are a few studies relating child BMI and dietary intake in young children ${ }^{(10-12)}$. Among school-aged children, higher vegetable consumption was associated with lower BMI among older girls $^{(13)}$ and sugar-sweetened beverage consumption with higher BMI among boys ${ }^{(14)}$. Fast-food purchasing increased the likelihood of being overweight for parents but not for their adolescent children ${ }^{(15)}$. Eating quick-service food twice weekly or more at baseline was positively associated with increase in BMI Z-score among 8-12-year-old girls three years later ${ }^{(16)}$.

Both physical activity and inactivity play roles in the development of obesity. Most studies have focused on 
psychosocial correlates of physical activity and sedentary behaviours ${ }^{(17)}$ and produced mixed results with weight status of young children ${ }^{(18)}$. There are no studies on correlates of physical activity in young American-Indian children, and a few studies with older American-Indian youth found positive correlations between television (TV) watching and prevalence of overweight or BMI ${ }^{(19,20)}$.

Examining factors within the home environment related to child overweight and obesity is essential to understanding the aetiology of these conditions and in developing interventions to prevent or reduce childhood obesity. Because of the high prevalence of overweight/obesity at early ages in American-Indian children and the likelihood of disparities associated with reservation life, it is especially important to understand if these factors contribute to obesity in children. The present study explored cross-sectional and prospective associations between aspects of the home environment specifically, parent report of food availability, child dietary intake frequency, child sedentary behaviours and parentperceived barriers to physical activity - and child BMI among young American-Indian children ( $4-8$ years) living on a reservation.

\section{Methods}

\section{Study sample and design}

The present research utilized cross-sectional and prospective analyses from the Bright Start study, a grouprandomized controlled obesity prevention trial. The aim of Bright Start was to reduce excess weight gain among American-Indian children residing on the Pine Ridge Reservation in South Dakota, primarily through dietary and physical activity environmental changes at school. All fourteen elementary schools on the reservation participated in the study. Two cohorts of kindergarten students were followed for 15 months to the end of 1st grade. Baseline data of the first and second cohorts were collected in autumn 2005 and autumn 2006, respectively, before schools were randomized to intervention and control conditions.

Children and parents had their heights and weights measured and parents completed a self-administered survey that assessed sociodemographic characteristics, home food and beverage availability, and their child's and their own dietary and physical activity behaviours. The survey was pilot tested with eleven Lakota parents of children of the approximate age of those in the Bright Start trial; revisions were made where necessary. In addition, the Tribal Review Board reviewed the survey for cultural appropriateness. Student anthropometric measures took place four times throughout the study (baseline, end of kindergarten, beginning and end of 1 st grade). For the present study, only baseline and roundfour (end of 1st grade) data were used. Body weight (kg) was measured to the nearest $100 \mathrm{~g}$ using a Tanita scale (model \# TBF300A; Tanita Corporation of America, Inc., Arlington Heights, IL, USA). Height (cm) was measured to the nearest $0 \cdot 1 \mathrm{~cm}$ using a portable stadiometer (Perspective Enterprises, Portage, MI, USA). Data were collected by trained study research staff, according to standardized protocols described by Lohman and colleagues ${ }^{(21)}$; students were measured in schools and parents in schools and community centres.

Letters of consent were received from the parents/ caregivers of all kindergarten students who were measured. Parents/caregivers included mother/stepmother (67\%), father/step-father (9\%), grandmother (16\%) and other (8\%). The other category included grandfather, aunt, uncle, guardian/foster parent, adoptive parent and other. Parents/caregivers will be termed parents for simplicity of reference. Of 472 kindergarten students enrolled across all schools at baseline, 454 children (96\%) had measures taken at baseline and 429 (94\%) at follow-up. Surveys were collected on 432 parents/guardians at baseline (95\%) and on 419 parents at follow-up (92\%); of these, 342 were the same parent/guardian at each time. Due to missing data, the current sample included 424 children. Study procedures were approved by the University of Minnesota's Institutional Review Board Human Subjects Committee, the Oglala Sioux Tribe and the Aberdeen Area Institutional Review Board.

\section{Measures}

\section{Dependent variables}

BMI was calculated from the measured weight and height $\left(\mathrm{kg} / \mathrm{m}^{2}\right)$ at baseline for the parents and children, and also at follow-up (end of 1st grade) for the children. For children, weight status categories were created using sexspecific BMI-for-age percentiles derived from the 2000 growth charts of the Centers for Disease Control and Prevention $^{(22)}$. Normal weight was defined as BMI $<85$ th percentile; overweight as $\mathrm{BMI} \geq 85$ th percentile but $<95$ th percentile; and obese as $\mathrm{BMI} \geq 95$ th percentile. There were only a few ( $n$ 19) underweight children (BMI $<5$ th percentile), thus they were included with normal weight children. For parents, normal weight was defined as BMI $<25 \mathrm{~kg} / \mathrm{m}^{2}$; overweight as BMI $\geq 25 \mathrm{~kg} / \mathrm{m}^{2}$ but $<30 \mathrm{~kg} / \mathrm{m}^{2}$; and obese as BMI $\geq 30 \mathrm{~kg} / \mathrm{m}^{2}$. There were no underweight parents.

\section{Independent variables}

Derivation of scales. Summative scales were derived for home food/beverage availability, child food/beverage intake, child screen time and physical activity. The derivation of any scale first involved factor analysis using all related items. Then the scale score was a simple sum over only those items within the first factor that had high internal consistency.

Home food/beverage availability. Parents reported whether forty-seven food and beverage items were available in their home in the past week (see Appendix). Response categories were ' $0=$ no' and ' $1=$ yes'. The home food/beverage availability questionnaire has been 
previously used in other studies with young children ${ }^{(23)}$ and demonstrated moderate test-retest reliability ${ }^{(24)}$. Categories of foods and beverages were created by summing the affirmative answers in each category. Two scales were created on the availability of healthful (Cronbach's $\alpha=0 \cdot 78$ ) and unhealthful (Cronbach's $\alpha=$ $0 \cdot 78$ ) foods/beverages. The fourteen-item scale describing availability of healthful foods included corn, peas, lettuce, carrots, tomatoes, green beans, broccoli, courgettes, other vegetables, peaches, pears, fruit cocktail, raisins and other fruits. The thirteen-item unhealthful food/beverage scale included fruit drinks, regular soda, Kool-Aid with sugar, sports drinks, French fries, potato chips (including corn chips, tortilla chips and Cheetos), cookies, doughnuts, cakes, candy, lunch meats, fried chicken and pizza.

Child food/beverage intake. In two separate questions, parents reported the frequency of their child's food and beverage (see Table 1 for content) consumption over the past month (see Appendix). Response categories were 'never', '1-3 times last month', '1-2 times a week', '3-4 times a week', '5-6 times a week', 'once a day' and 'more than once a day'. For the multivariable analysis, the frequencies were converted to occasions/d using the approximate equivalents $(0,0 \cdot 1,0 \cdot 2$, $0 \cdot 5,0 \cdot 8,1 \cdot 0,2 \cdot 0$ times/d) and modelled as continuous variables. One three-item scale describing consumption of sugarsweetened beverages was created (Cronbach's $\alpha=0 \cdot 64$ ). The scale included fruit drinks (Snapple, Hi-C, Sunny D, Bug Juice, fruit punch), Kool-Aid with sugar and regular soda.

Child screen time and physical activity. In separate questions, parents reported daily child screen time including TV and computer games during school days. The questions have been used previously, demonstrating acceptable reliability ${ }^{(23)}$. A three-item scale indicating parent report of his/her child's play outdoors was created (Cronbach's $\alpha=0 \cdot 71$ ). A five-item scale describing child and parent engaging in physical activity together was created (Cronbach's $\alpha=0 \cdot 78$ ). Examples of items included 'I do something physically active each week with my child' and 'When the weather is nice I go for a walk with my child'. Five response categories ranged from 'never' to 'always'. A seven-item scale was created to indicate parents' perceived barriers to their child's physical activity and screen time behaviour (Cronbach's $\alpha=0 \cdot 66$ ). Examples of items included 'Where we live it is safe for a child to play outdoors' and 'My child spends too much time playing video games'. Four response categories ranged from 'strongly agree' to 'strongly disagree'. Higher scores indicate more barriers.

Demographic characteristics. Child age at baseline was calculated using parent report of the date of birth. Principal component factor analysis was used to create a socio-economic status variable by combining items in five areas from the parent survey (i.e. parent education level, household income, unemployment, public assistance and resources in the home). This factor explained $42 \%$ of the variation in the data. To validate this measure, three individuals familiar with the reservation and all of the schools ranked the schools for socio-economic status. Spearman rank correlations between these expert assessments and the mean 'relative SES' factor were high $(0 \cdot 78$ and $0 \cdot 88$ ). The factor score is referred to as 'relative SES (rSES)' to emphasize that it is specific to the Bright Start population.

\section{Statistical analysis}

Descriptive statistics were used for demographic characteristics, frequencies of the home food/beverage availability and mean values of children's dietary intake frequency. Results for the outcome variable child BMI were reported as the probabilities of being normal weight, overweight or obese, which were calculated using inverse transformations of the logit function. Mixed model analysis of variance (PROC GLIMMIX) was used to examine cross-sectional and prospective associations between child BMI percentile categories and the home environment variables. In the prospective models, the associations between change in the predictor variables and child BMI at follow-up conditional on baseline weight status were examined. The predicted probabilities for each weight status at follow-up were reported for each weight status category at baseline. Separate analyses were conducted for each independent/dependent variable combination. All multivariable analyses were adjusted for baseline child age, gender, rSES and parent BMI. Prospective models were also adjusted for baseline outcome variables (child BMI), baseline predictors, age difference and study condition (intervention and control). The school variable was included in all the models as a random effect, accounting for the additional component of variance associated with a cluster sampling design where observations from students from the same schools may be correlated ${ }^{(25)}$. There were no gender differences in the associations between predictors and child BMI after controlling for covariates; thus, the final models pooled the genders. The $P$ values are not used for hypothesis testing because we do not have a priori null hypotheses. Instead, $P$ values are used to point to potentially interesting correlations between the outcome variable and predictors; thus we did not adjust the significance level to reflect multiple tests. All analyses were completed using the SAS statistical software package version $9 \cdot 2$ (SAS Institute, Cary, NC, USA).

\section{Results}

There were $51 \%$ male and $49 \%$ female children with a mean age at baseline of $5 \cdot 8(\mathrm{sD} 0 \cdot 5)$ years (range $4 \cdot 7-7 \cdot 9$ years). At baseline, $29 \%$ of the children were overweight or obese. The majority of parents in the study were female $(89 \%)$ and $86 \%$ (mean age $35 \cdot 6$ (SD 10.7) years; range $19 \cdot 2-74 \cdot 0$ years) were overweight or obese (BMI $\geq$ $25 \mathrm{~kg} / \mathrm{m}^{2}$; mean BMI $32.5(\mathrm{sD} 7 \cdot 3) \mathrm{kg} / \mathrm{m}^{2}$ ). On average, parents reported $6 \cdot 4$ different types of vegetables and $5 \cdot 7$ different types of fruits available at home in the past week. 
Table 1 Weekly average number of foods and beverages available at home by child gender- and age-adjusted BMI percentile categories at baseline $(n 424)^{*}$ as reported by parents/caregivers; kindergarten American-Indian children, Bright Start school-based obesity prevention trial, South Dakota, USA

\begin{tabular}{|c|c|c|c|c|c|c|c|c|c|c|c|c|}
\hline \multirow[b]{3}{*}{ Home food availability (number per week) $\dagger$} & & & \multicolumn{9}{|c|}{ Child BMI percentiles } & \multirow[b]{3}{*}{$P$ values } \\
\hline & \multicolumn{2}{|c|}{ Total } & \multicolumn{3}{|c|}{$<85$ th } & \multicolumn{3}{|c|}{$\geq 85$ th $-<95$ th } & \multicolumn{3}{|c|}{$\geq 95$ th } & \\
\hline & Mean & SD & Mean & SD & $n$ & Mean & SD & $n$ & Mean & SD & $n$ & \\
\hline Vegetables without potatoes $\|$ & $6 \cdot 4$ & $1 \cdot 8$ & $6 \cdot 4$ & $1 \cdot 8$ & 291 & $6 \cdot 3$ & $1 \cdot 5$ & 61 & $6 \cdot 0$ & $2 \cdot 1$ & 64 & 0.283 \\
\hline Fruits & $5 \cdot 7$ & $1 \cdot 8$ & $5 \cdot 6$ & $1 \cdot 8$ & 291 & $5 \cdot 8$ & $1 \cdot 8$ & 61 & $5 \cdot 5$ & 1.9 & 64 & 0.665 \\
\hline Sugar-sweetened beverages** & $1 \cdot 8$ & $1 \cdot 0$ & $1 \cdot 8$ & $1 \cdot 0$ & 290 & $1 \cdot 8$ & 0.9 & 61 & $1 \cdot 6$ & 0.9 & 63 & 0.403 \\
\hline Salty snackstt & $1 \cdot 4$ & $0 \cdot 8$ & $1 \cdot 4$ & 0.8 & 293 & $1 \cdot 3$ & 0.7 & 61 & 1.5 & 0.9 & 64 & $0 \cdot 199$ \\
\hline Sweet snacksł & $2 \cdot 6$ & $1 \cdot 4$ & $2 \cdot 7$ & $1 \cdot 4$ & 293 & $2 \cdot 5$ & $1 \cdot 3$ & 61 & $2 \cdot 5$ & $1 \cdot 3$ & 64 & 0.545 \\
\hline Healthful food score $\S \S$ & $9 \cdot 5$ & $2 \cdot 9$ & $9 \cdot 6$ & $2 \cdot 9$ & 291 & $9 \cdot 6$ & $2 \cdot 5$ & 61 & $8 \cdot 9$ & $3 \cdot 4$ & 61 & $0 \cdot 264$ \\
\hline \multirow[t]{2}{*}{ Unhealthful food score \|\|} & $7 \cdot 9$ & $3 \cdot 1$ & $7 \cdot 9$ & $3 \cdot 1$ & 292 & $7 \cdot 5$ & $2 \cdot 7$ & 61 & $7 \cdot 6$ & $2 \cdot 7$ & 64 & 0.504 \\
\hline & \multicolumn{2}{|c|}{$\%$} & \multicolumn{2}{|c|}{$\%$} & $n$ & \multicolumn{2}{|c|}{$\%$} & $n$ & \multicolumn{2}{|c|}{$\%$} & $n$ & \\
\hline Whole milk $(\%)^{\star \star \star}$ & \multirow{2}{*}{\multicolumn{2}{|c|}{$\begin{array}{l}55 \cdot 2 \\
17 \cdot 9\end{array}$}} & \multirow{2}{*}{\multicolumn{2}{|c|}{$\begin{array}{l}57 \cdot 4 \\
16 \cdot 4\end{array}$}} & 289 & \multirow{2}{*}{\multicolumn{2}{|c|}{$\begin{array}{l}60 \cdot 6 \\
24 \cdot 1\end{array}$}} & 61 & \multirow{2}{*}{\multicolumn{2}{|c|}{$\begin{array}{l}39.6 \\
18.6\end{array}$}} & 63 & 0.024 \\
\hline Skimmed or $1 \%$ milk $(\%)^{\star * *}$ & & & & & 285 & & & 58 & & & 59 & 0.380 \\
\hline
\end{tabular}

*Sample size may slightly vary in each analysis due to incidental missing data.

tResponse categories for each item included ' $\mathrm{No}=0$ ' and ' $Y$ es $=1$ '. Items in the food and beverage categories were summed to calculate the total number of affirmative responses.

$\ddagger$ The mean represents the average number of the different foods or beverages under each category that were available at home in the past week.

$\S P$ value refers to level of significance of the unadjusted associations between child BMI percentiles and home food availability.

$\|$ Vegetables without potatoes include corn, peas, lettuce, carrots, tomatoes, green beans, broccoli, courgettes and other vegetables.

TFruits include apples or apple sauce, bananas, oranges, peaches, pears, fruit cocktail, raisins and other fruits

${ }^{* *}$ Sugar-sweetened beverages include fruit drinks, regular pop and Kool-Aid.

t+Salty snacks include potato chips (corn chips, tortilla chips and Cheetos), pretzels and sunflower seeds.

$\ddagger \ddagger$ Sweet snacks include cake, cookies, pies, ice cream, doughnuts, sweet rolls, Pop-tarts, muffins and candy.

$\S \S$ Healthful foods include corn, peas, lettuce, carrots, tomatoes, green beans, broccoli, courgettes, other vegetables, peaches, pears, fruit cocktail, raisins and other fruit.

\|IIUnhealthful foods include fruit drinks, regular pop, Kool-Aid, sports drinks, French fries, potato chips, cookies, snack cakes, doughnuts, candy, lunch meat, fried chicken and pizza.

${ }^{\star * \star}$ The percentage of parents who reported having that type of milk in their homes during the past week.

Table 2 Frequency of child dietary intake at baseline $(n 424)^{\star}$ as reported by parents/caregivers; kindergarten American-Indian children, Bright Start school-based obesity prevention trial, South Dakota, USA

\begin{tabular}{|c|c|c|c|c|c|c|}
\hline \multirow[b]{3}{*}{ Dietary intake frequency } & \multicolumn{6}{|c|}{ Child dietary intake over the past month } \\
\hline & \multicolumn{2}{|c|}{ Never to 2 times weekly } & \multicolumn{2}{|c|}{3 to 6 times weekly } & \multicolumn{2}{|c|}{ Once daily or more } \\
\hline & $n$ & $\%$ & $n$ & $\%$ & $n$ & $\%$ \\
\hline Vegetables (no potatoes) & 109 & 26 & 172 & 41 & 139 & 33 \\
\hline Fruits & 95 & 23 & 161 & 38 & 163 & 39 \\
\hline Whole milk & 91 & 22 & 123 & 30 & 199 & 48 \\
\hline Skimmed milk & 276 & 67 & 61 & 15 & 72 & 18 \\
\hline $100 \%$ fruit juice & 119 & 28 & 188 & 45 & 113 & 27 \\
\hline Regular soda & 327 & 79 & 58 & 14 & 31 & 7 \\
\hline Kool-Aid & 259 & 62 & 95 & 23 & 61 & 15 \\
\hline Fruit drinks & 261 & 62 & 112 & 27 & 46 & 11 \\
\hline Fast food & 368 & 88 & 38 & 9 & 13 & 3 \\
\hline
\end{tabular}

*Sample size may slightly vary due to incidental missing data.

There were no significant differences in the home food availability among child BMI categories, with the exception of whole milk which was more available in homes of overweight children (Table 1). Over the past month, about a quarter of children consumed vegetables or fruits either never or only two times weekly and a third of them had these foods once daily or more. Whole milk was the most frequently consumed type of milk; close to $50 \%$ of children consumed whole milk once daily or more, whereas only $19 \%$ of them consumed skimmed milk this often (Table 2).
On average, children spent $2 \mathrm{~h}$ watching TV and $0.6 \mathrm{~h}$ playing video games per school day (Table 3). About $60 \%$ of parents reported being physically active with their child each week and about $75 \%$ reported that their child often or always plays outdoors after school. The vast majority of parents $(93 \%)$ reported that their child gets enough physical activity based on their own assessment of what was 'enough physical activity'; they also reported that it was safe to play outdoors (85\%). In contrast, about half the parents did not think there were places to be active in the community, and about a third did not think 
Table 3 Child baseline physical activity and screen time at baseline $(n 424)^{\star}$ as reported by parents/caregivers; kindergarten AmericanIndian children, Bright Start school-based obesity prevention trial, South Dakota, USA

\begin{tabular}{|c|c|c|c|c|}
\hline & $n$ & Mean & & SD \\
\hline Child television/screen time during school days $(\mathrm{h} / \mathrm{d})$ & 423 & $2 \cdot 0$ & & $1 \cdot 4$ \\
\hline \multirow[t]{2}{*}{ Child computer/video games during school days $(\mathrm{h} / \mathrm{d})$} & 424 & 0.6 & & $0 \cdot 9$ \\
\hline & $n$ & & $\%$ & \\
\hline \multicolumn{5}{|c|}{ Parent and child activity scale (Cronbach's $\alpha=0.78$; mean 18; range 8-25) $\dagger$} \\
\hline \multicolumn{5}{|l|}{ Often, always (\%) } \\
\hline Parent physically active with child each week & 422 & & $60 \cdot 1$ & \\
\hline Parent walk with child & 421 & & $55 \cdot 1$ & \\
\hline How often does family go on walks together? & 419 & & $39 \cdot 9$ & \\
\hline How often does family play games together? & 423 & & $42 \cdot 5$ & \\
\hline How often limit on child's television & 422 & & $44 \cdot 3$ & \\
\hline \multicolumn{5}{|c|}{ Child play outdoors scale (Cronbach's $\alpha=0.71$; mean 13; range 6-15) $\dagger$} \\
\hline \multicolumn{5}{|l|}{ Often, always (\%) } \\
\hline Child plays outdoors when weather is nice & 423 & & $86 \cdot 3$ & \\
\hline How often child plays outdoors after school & 422 & & $74 \cdot 2$ & \\
\hline How often child plays outdoors on weekends & 420 & & $80 \cdot 0$ & \\
\hline \multicolumn{5}{|c|}{$\begin{array}{l}\text { Parent-perceived barriers for physical activity and screen time behaviour scale (Cronbach's } \alpha=0.66 \text {; } \\
\text { mean 14; range 7-23) }\end{array}$} \\
\hline \multicolumn{5}{|l|}{ Strongly agree, agree $(\%) \ddagger$} \\
\hline It's safe to play outdoors & 421 & & $84 \cdot 8$ & \\
\hline Child gets enough physical activity & 423 & & $92 \cdot 9$ & \\
\hline There are places the child can play near the house & 420 & & $67 \cdot 8$ & \\
\hline Places in the community for child to be physically active & 422 & & $54 \cdot 3$ & \\
\hline Too much time watching television & 421 & & $22 \cdot 5$ & \\
\hline Too much time playing video games & 418 & & $15 \cdot 1$ & \\
\hline Easy to limit amount of television child watches & 422 & & $81 \cdot 3$ & \\
\hline
\end{tabular}

*Sample size may slightly vary due to incidental missing data.

tResponse categories: $1=$ never, 2 = rarely, $3=$ sometimes, $4=$ often, $5=$ always.

‡Response categories: 1 = strongly agree, $2=$ agree, $3=$ disagree, $4=$ strongly disagree

there were places near the house for their child to be physically active.

\section{Cross-sectional associations}

Table 4 shows cross-sectional associations between the probability of a child being in a specific weight status and the home environment. With regard to home food availability and child BMI, the probability of being at normal weight, overweight or obese was very similar at the mean level of each explanatory variable. Our models allow us to compare the child weight status between two families which differ in home food availability by one standard deviation. For example, in families with higher availability of different vegetables without potatoes (one standard deviation higher) the probability of a child being at normal weight was higher by $4 \cdot 1 \%$ (from $71 \cdot 3 \%$ to $75 \cdot 4 \%$ ), whereas the probability of being obese was lower by $2 \cdot 3 \%$ (from $13.5 \%$ to $11 \cdot 2 \%$ ). For vegetable and healthful food availability where the association with child BMI was statistically stronger, the difference in probabilities for each weight category was larger than in other food and beverage groups. For child intake frequency of vegetables, fruits and $100 \%$ juice, the change in probabilities of being at normal weight, overweight or obese was in the expected direction. For example, in homes where child intakes were higher by one standard deviation, the probability of being at normal weight was higher and the probabilities of being overweight or obese were lower. The opposite was true for unhealthful foods/beverages with the exception of whole and skimmed milk intake. The more barriers to physical activity and screen time the parents perceived, the lower was the probability of a child being at normal weight and the higher the probability of a child being overweight and obese. Parent BMI was the most significant correlate of child weight status $(P<0 \cdot 0001)$ in all models (data not shown).

\section{Prospective associations}

Table 5 presents prospective associations between change in the home environment and subsequent child weight status categories at follow-up conditional on baseline weight status between two families; one family follows the average response in availability or intake and the other changes by one standard deviation above the average. For example, a child at normal weight at baseline who is in a family with availability of different sweet snacks one standard deviation above the average will have $5.3 \%$ decreased probability (from $80.0 \%$ to $74 \cdot 7 \%$ ) of being at normal weight at follow-up and $4 \cdot 3 \%$ increased probability (from $17 \cdot 3 \%$ to $21 \cdot 6 \%$ ) of being overweight at follow-up. Because of the large number of potential variables, only the most interesting correlates at $P<0 \cdot 20$ are presented. Overall, baseline child weight status was the major significant predictor of weight status at follow-up $(P<0 \cdot 0001)$ followed by parent baseline BMI. There were no significant prospective associations of child 
Table 4 Cross-sectional associations between probability of a child belonging in a specific weight category and parent report of $\mathrm{food} / \mathrm{beverage}$ availability, child dietary intake frequency, and perceived barriers to physical activity and screen time behaviours at baseline $(n$ 424)*; kindergarten American-Indian children, Bright Start school-based obesity prevention trial, South Dakota, USA

\begin{tabular}{|c|c|c|c|c|c|c|c|}
\hline & \multicolumn{6}{|c|}{ Probability of child weight status at baseline } & \multirow[b]{3}{*}{$\begin{array}{c}P \\
\text { value }\end{array}$} \\
\hline & \multicolumn{2}{|c|}{ Normal weight } & \multicolumn{2}{|c|}{ Overweight } & \multicolumn{2}{|c|}{ Obese } & \\
\hline & $\begin{array}{l}\text { Probability at the } \\
\text { mean level }(\%)+\end{array}$ & $\begin{array}{l}\text { Difference } \\
\quad(\%) \ddagger\end{array}$ & $\begin{array}{l}\text { Probability at the } \\
\text { mean level }(\%)+\end{array}$ & $\begin{array}{l}\text { Difference } \\
\quad(\%) \ddagger\end{array}$ & $\begin{array}{l}\text { Probability at the } \\
\text { mean level }(\%)+\end{array}$ & $\begin{array}{l}\text { Difference } \\
\qquad(\%) \ddagger\end{array}$ & \\
\hline \multicolumn{8}{|l|}{ Food/beverage availability\| } \\
\hline Vegetables without potatoes & $71 \cdot 3$ & $4 \cdot 1$ & $15 \cdot 2$ & $-1 \cdot 8$ & $13 \cdot 3$ & $-2 \cdot 3$ & 0.051 \\
\hline Fruits $^{\star \star}$ & $71 \cdot 2$ & $0 \cdot 9$ & $15 \cdot 2$ & $-0 \cdot 4$ & $13 \cdot 5$ & -0.5 & 0.681 \\
\hline Sugar-sweetened beveragestt & $71 \cdot 3$ & $2 \cdot 7$ & $15 \cdot 2$ & $-1 \cdot 2$ & $13 \cdot 3$ & $-1 \cdot 5$ & $0 \cdot 215$ \\
\hline Whole milk & $71 \cdot 2$ & 0.02 & $15 \cdot 3$ & $-0 \cdot 01$ & $13 \cdot 4$ & $-0 \cdot 01$ & $0 \cdot 271$ \\
\hline Skimmed milk & $72 \cdot 3$ & $-1 \cdot 1$ & $14 \cdot 9$ & 0.5 & $12 \cdot 7$ & $0 \cdot 6$ & 0.623 \\
\hline Salty snacksłł & $71 \cdot 4$ & 0 & $15 \cdot 1$ & 0.0 & $13 \cdot 4$ & $0 \cdot 0$ & 0.995 \\
\hline Sweet snacks $\S$ & $71 \cdot 5$ & $2 \cdot 2$ & $15 \cdot 1$ & $-1 \cdot 0$ & $13 \cdot 3$ & $-1 \cdot 2$ & 0.308 \\
\hline Healthful food score \|\| & $71 \cdot 3$ & $3 \cdot 6$ & $15 \cdot 3$ & $-1 \cdot 7$ & $13 \cdot 3$ & -1.9 & 0.094 \\
\hline Unhealthful food score ${ }^{\star \star \star}$ & $71 \cdot 5$ & $2 \cdot 4$ & $15 \cdot 1$ & $-1 \cdot 1$ & $13 \cdot 3$ & $-1 \cdot 4$ & 0.266 \\
\hline \multicolumn{8}{|l|}{ Dietary intake frequency (times/d) } \\
\hline Vegetables (no potatoes) & $71 \cdot 7$ & $4 \cdot 0$ & $15 \cdot 0$ & $-1 \cdot 8$ & $13 \cdot 1$ & $-2 \cdot 2$ & 0.073 \\
\hline Fruits & $71 \cdot 0$ & $2 \cdot 3$ & $15 \cdot 4$ & $-1 \cdot 1$ & $13 \cdot 5$ & $-1 \cdot 3$ & $0 \cdot 301$ \\
\hline Sugar-sweetened beverages & $71 \cdot 4$ & $-2 \cdot 2$ & $15 \cdot 1$ & 0.9 & $13 \cdot 3$ & $1 \cdot 3$ & 0.338 \\
\hline Whole milk & $71 \cdot 0$ & $3 \cdot 1$ & $15 \cdot 5$ & $-1 \cdot 4$ & $13 \cdot 4$ & $-1 \cdot 7$ & 0.174 \\
\hline Skimmed milk & $71 \cdot 1$ & $-4 \cdot 2$ & $15 \cdot 3$ & $1 \cdot 8$ & $13 \cdot 4$ & $2 \cdot 5$ & 0.057 \\
\hline $100 \%$ fruit juice & $71 \cdot 1$ & $2 \cdot 6$ & $15 \cdot 3$ & $-1 \cdot 2$ & $13 \cdot 4$ & $-1 \cdot 3$ & $0 \cdot 244$ \\
\hline Fast food & $71 \cdot 4$ & $-4 \cdot 4$ & $15 \cdot 0$ & $1 \cdot 8$ & $13 \cdot 4$ & $2 \cdot 6$ & 0.056 \\
\hline \multicolumn{8}{|l|}{ Physical activity and screen time } \\
\hline Child plays outdoors & $71 \cdot 4$ & $3 \cdot 1$ & $15 \cdot 1$ & $-1 \cdot 4$ & $13 \cdot 3$ & $-1 \cdot 7$ & $0 \cdot 169$ \\
\hline Parent-child activities together & $71 \cdot 3$ & 0.9 & $15 \cdot 1$ & $-0 \cdot 4$ & $13 \cdot 4$ & -0.5 & 0.685 \\
\hline $\begin{array}{l}\text { Child television/screen time on } \\
\text { school days }(\mathrm{h} / \mathrm{d})\end{array}$ & $71 \cdot 4$ & $2 \cdot 8$ & $15 \cdot 1$ & $-1 \cdot 3$ & $13 \cdot 4$ & $-1 \cdot 6$ & 0.224 \\
\hline $\begin{array}{l}\text { Child computer/video time on } \\
\text { school days }(\mathrm{h} / \mathrm{d})\end{array}$ & $71 \cdot 4$ & $2 \cdot 5$ & $15 \cdot 1$ & $-1 \cdot 1$ & $13 \cdot 3$ & $-1 \cdot 4$ & 0.288 \\
\hline $\begin{array}{l}\text { Parent-perceived barriers to } \\
\text { physical activity and screen time }\end{array}$ & $71 \cdot 9$ & $-5 \cdot 3$ & $15 \cdot 2$ & $1 \cdot 9$ & $13 \cdot 4$ & $2 \cdot 7$ & 0.052 \\
\hline
\end{tabular}

*Sample size may slightly vary in each analysis due to incidental missing data; all analyses were adjusted for child age, gender, relative socio-economic status specific to Bright Start population, and parent BMI.

tAt the mean level of each predictor.

‡Difference in probability of being in the indicated weight status for a child in a family with average level of home environment variables compared to a child in a family for which these variables are $1 \mathrm{SD}$ higher than the average.

$\S$ The $P$ value indicates the level of significance between the explanatory variable and the outcome (child weight status).

$\|$ Response categories for each item included ' $\mathrm{No}=0$ ' and 'Yes =1'. Items in the food and beverage categories were summed to calculate the total number of affirmative responses.

TVegetables without potatoes include corn, peas, lettuce, carrots, tomatoes, green beans, broccoli, courgettes and other vegetables.

${ }^{\star *}$ Fruits include apples or apple sauce, bananas, oranges, peaches, pears, fruit cocktail, raisins and other fruits.

t+Sugar-sweetened beverages include fruit drinks, regular pop and Kool-Aid.

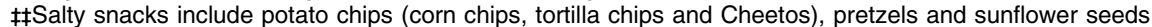

$\S \S$ Sweet snacks include cake, cookies, pies, ice cream, doughnuts, sweet rolls, Pop-tarts, muffins and candy.

\|\| Healthful foods include corn, peas, lettuce, carrots, tomatoes, green beans, broccoli, courgettes, other vegetables, peaches, pears, fruit cocktail, raisins and other fruit.

***Unhealthful foods include fruit drinks, regular pop, Kool-Aid, sports drinks, French fries, potato chips, cookies, snack cakes, doughnuts, candy, lunch meat, fried chicken and pizza.

sedentary activities, parent-perceived barriers about screen time and physical activity and parent-child physical activity with child BMI categories.

\section{Discussion}

The present study examined cross-sectional and prospective associations between home environmental factors and child BMI among young American-Indian children living on a reservation. Our findings indicate relatively low frequencies of fruit and vegetable consumption and are consistent with previous studies among American-Indian children living on a reservation $^{(26)}$ or in urban areas ${ }^{(20)}$.
The study findings indicated interesting associations between child weight status and parent report of the home environment. Cross-sectional associations showed that children in families with higher vegetable and healthful food availability and more frequent vegetable intake had higher probability of being at normal weight and lower probability of being overweight or obese. Previous research failed to show associations between home food availability and BMI among American Indians ${ }^{(20,27)}$ and among children from other racial groups ${ }^{(8)}$.

More consistent results have been observed with higher vegetable consumption and lower child BMI among slightly older children than our sample ${ }^{(13)}$. Children with more frequent skimmed milk consumption had 
Table 5 Prospective associations between predicted shifts in probability of a child belonging to a category of weight status at follow-up and changes in the parent report of food/beverage availability and child dietary intake frequency from baseline to follow-up ( $n$ 424)*; kindergarten American-Indian children, Bright Start school-based obesity prevention trial, South Dakota, USA

\begin{tabular}{|c|c|c|c|c|c|c|c|}
\hline & \multicolumn{6}{|c|}{ Predicted probability of child weight status at follow-up } & \multirow[b]{3}{*}{$\begin{array}{c}P \\
\text { value§ }\end{array}$} \\
\hline & \multicolumn{2}{|c|}{ Normal weight } & \multicolumn{2}{|c|}{ Overweight } & \multicolumn{2}{|c|}{ Obese } & \\
\hline & $\begin{array}{l}\text { Probability } \\
\text { at the mean } \\
\text { change of } \\
\text { predictor } \\
(\%)+\end{array}$ & $\begin{array}{l}\text { Change in } \\
\text { probability for } \\
1 \text { sD higher } \\
\text { change in } \\
\text { predictor (\%)‡ }\end{array}$ & $\begin{array}{l}\text { Probability } \\
\text { at the mean } \\
\text { change of } \\
\text { predictor } \\
(\%)+\end{array}$ & $\begin{array}{l}\text { Change in } \\
\text { probability for } \\
1 \text { SD higher } \\
\text { change in } \\
\text { predictor (\%)‡ }\end{array}$ & $\begin{array}{l}\text { Probability } \\
\text { at the mean } \\
\text { change of } \\
\text { predictor } \\
(\%)+\end{array}$ & $\begin{array}{l}\text { Change in } \\
\text { probability for } \\
1 \text { sD higher } \\
\text { change in } \\
\text { predictor }(\%) \ddagger\end{array}$ & \\
\hline \multicolumn{8}{|l|}{ Food/beverage availability\| } \\
\hline Sweet snacks & & & & & & & 0.050 \\
\hline Normal weight at baseline & $80 \cdot 0$ & $-5 \cdot 3$ & $17 \cdot 3$ & $4 \cdot 3$ & $2 \cdot 6$ & 0.9 & \\
\hline Overweight at baseline & $8 \cdot 5$ & $-2 \cdot 1$ & $37 \cdot 6$ & $-5 \cdot 3$ & $53 \cdot 8$ & $7 \cdot 3$ & \\
\hline Obese at baseline & $1 \cdot 2$ & -0.3 & $9 \cdot 0$ & $-2 \cdot 2$ & $89 \cdot 7$ & $2 \cdot 5$ & \\
\hline Unhealthful food score ${ }^{\star \star}$ & & & & & & & $0 \cdot 176$ \\
\hline Normal weight at baseline & $79 \cdot 8$ & $-3 \cdot 5$ & $17 \cdot 3$ & $3 \cdot 0$ & $2 \cdot 7$ & $0 \cdot 6$ & \\
\hline Overweight at baseline & $8 \cdot 5$ & $-1 \cdot 5$ & $37 \cdot 1$ & $-3 \cdot 6$ & $54 \cdot 3$ & $5 \cdot 1$ & \\
\hline Obese at baseline & $1 \cdot 3$ & -0.3 & 9.5 & $-1 \cdot 7$ & $89 \cdot 1$ & 1.9 & \\
\hline \multicolumn{8}{|l|}{ Dietary intake frequency } \\
\hline Fruitstt & & & & & & & $0 \cdot 123$ \\
\hline Normal weight at baseline & $81 \cdot 9$ & $-3 \cdot 4$ & $15 \cdot 6$ & $2 \cdot 8$ & $2 \cdot 3$ & $0 \cdot 6$ & \\
\hline Overweight at baseline & $9 \cdot 8$ & $-1 \cdot 7$ & $39 \cdot 5$ & $-3 \cdot 6$ & $50 \cdot 6$ & $5 \cdot 3$ & \\
\hline Obese at baseline & $1 \cdot 5$ & -0.3 & $10 \cdot 7$ & $-1 \cdot 8$ & $87 \cdot 6$ & $2 \cdot 2$ & \\
\hline $100 \%$ fruit juice & & & & & & & $0 \cdot 151$ \\
\hline Normal weight at baseline & $82 \cdot 7$ & -2.9 & $14 \cdot 9$ & $2 \cdot 5$ & $2 \cdot 2$ & 0.5 & \\
\hline Overweight at baseline & $9 \cdot 9$ & $-1 \cdot 6$ & $39 \cdot 8$ & $-3 \cdot 2$ & $50 \cdot 1$ & $4 \cdot 8$ & \\
\hline Obese at baseline & $1 \cdot 6$ & -0.3 & $11 \cdot 3$ & $-1 \cdot 7$ & $86 \cdot 9$ & 2.1 & \\
\hline
\end{tabular}

*Sample size may slightly vary in each analysis due to incidental missing data; all analyses were adjusted for baseline child age, gender, parent BMI, baseline predictors, age difference, study condition and relative socio-economic status (specific to the Bright Start population).

tAt the mean level of each predictor.

¥Predicted shifts in probability of a child belonging to a category of weight status at follow-up conditional on initial category; comparing a child in a family for which availability or intake increases from baseline to follow-up by 1 SD above average $v$. the probability for a child in a family with just average change. $\S$ The $P$ value indicates the level of significance between the explanatory variable and the outcome (child weight status).

$\|$ Response categories for each item included ' $\mathrm{No}=0$ ' and 'Yes $=1$ '. Items in the food and beverage categories were summed to calculate the total number. $\uparrow$ Sweet snacks include cake, cookies, pies, ice cream, doughnuts, sweet rolls, Pop-tarts, muffins and candy.

**Unhealthful foods include fruit drinks, regular pop, Kool-Aid, sports drinks, French fries, potato chips, cookies, snack cakes, doughnuts, candy, lunch meat, fried chicken and pizza.

t+Fruits include apples or apple sauce, bananas, oranges, peaches, pears, fruit cocktail, raisins and other fruits.

a higher baseline probability of being overweight and obese and a lower probability of being at normal weight. Although this association was not in the anticipated direction, other studies with older children (9-14 years) found similar results ${ }^{(28)}$, attributing them to increased energy intake ${ }^{(28)}$. Reverse causation may be present as overweight/obese children may increase intake of skimmed milk to prevent further weight gain.

Fast-food consumption frequency one standard deviation higher than the mean at baseline was associated with a higher probability of a child being overweight or obese and with a lower probability of being at normal weight. Since there are only a few fast- food restaurants on the reservation, fast foods in the present study also includes foods purchased from convenience stores that sell fast foods as well. Other studies have also shown that fastfood purchases are positively associated with increased BMI Z-scores among children and adolescents ${ }^{(16)}$ and with increased likelihood of being overweight among adults $^{(15)}$. Fast foods tend to cost less than healthful foods; therefore, they may appear more practical for those who are economically disadvantaged ${ }^{(29)}$.
The children in our study spent fewer hours watching TV and playing video games per school week day than other 5-6-year-old American-Indian children living in urban settings ${ }^{(20)}$. The discrepancy may be partly due to measurement differences; in our study children's screen time was reported by parents, whereas in Gray and Smith's study it was reported by children ${ }^{(20)}$. Previous findings have shown higher BMI with higher levels of TV watching in 8-12-year-old American-Indian children ${ }^{(30)}$ and among the general population of 6-year-olds ${ }^{(31)}$. However, in our study, screen time was not associated with children's BMI categories. In Saelens et al.'s study TV time included both school and weekend days, whereas we included only school days; this may have contributed to the lower average TV watching among our children ${ }^{(31)}$, since screen time may be higher on weekends.

An interesting finding was the association between parents' perceptions of barriers to physical activity and screen time and a higher probability of a child being overweight or obese at baseline. It is difficult to compare our findings directly with those of other studies because of differences in measurement. In another study, 8-12-year-old 
American-Indian children living on a reservation reported feeling unsafe when using their community bike path and a lack of resources to engage in physical activities ${ }^{(30)}$. Focus groups found similar concerns by American-Indian parents, who were reluctant to let their children play outdoors due to safety concerns and instead let them watch more $\mathrm{TV}^{(32)}$. Although causal inferences cannot be drawn from our cross-sectional findings, it may be important to consider barriers perceived by parents, especially of obese children, when developing measurements and interventions.

Prospectively we found few associations between categories of child BMI and home environment variables. Only the home availability of sweet snacks predicted an increased probability of being overweight and obese two years later for those who were at normal weight at baseline. The limited variation in the change of the predictor variables may be one factor that contributed to the lack of significant prospective findings. It is possible that the relatively strong effects of parent and child weight status at baseline attenuated any potential associations between variables of the home environment and child BMI at follow-up.

The two most significant and consistent predictors of child weight status were parent weight status in crosssectional models and parent and child baseline weight status prospectively. There is evidence supporting these associations among the general population ${ }^{(33,34)}$. A retrospective cohort study of mainly white young adults indicated that when children were younger than 3 years, parent obesity status was the primary predictor of obesity in adulthood, whereas for children aged 3 to 9 years, parents' and children's obesity status became the primary predictor of obesity in adulthood ${ }^{(33)}$. As the children progressed to older age, the children's obesity status remained the strongest predictor ${ }^{(33)}$. Given the high prevalence of obesity among American-Indian populations, it is important that childhood obesity prevention programmes focus on preventing obesity and improving dietary behaviours of parents.

The findings of our study add to the limited research on the home environment and weight status of young American-Indian children. The inclusion of home food availability, dietary intake frequency of children and physical activity-related variables provides a more complete picture of the home environment on children's weight status. The comparison of the three weight categories permits the detection of differences in the home environment between categories. Finally, the inclusion of both cross-sectional and prospective data permits inferences about temporal associations.

Study limitations include the use of parent reports for the home environment, which may be subject to desirability bias and represents perceived rather than actual behaviours. Also, some parents may not be fully aware of the food their children consume at school. Fruit and vegetable consumption were each measured with a single question which may not capture the extent of intake of these foods and may lead to underestimation. The home food/beverage availability measure was adapted from a previously validated questionnaire with slightly older African-American children. Although all the scales do not contain the same number of items, we are looking at the relative difference within each scale to predict child BMI, and we are not comparing two scales of different foods with varied number of items. We did not measure the amount of foods; rather we measured the types of foods available. The amount of what is available at home might have more to do with consumption and therefore weight. Our measure does not address the fact that some families might have few different types of foods available but might have a lot of them, while other families might have a wide variety of foods available but have limited amounts. Parents reported availability and consumption of foods at home; however, since all children on the reservation are eligible for free school breakfast and lunch meals, availability of food at schools also plays an important role in children's overall dietary consumption.

Although the results are important for American-Indian children and families living on a reservation, they may not be applicable to other populations of children, especially older, more independent school-aged children.

\section{Conclusions}

The findings of the present study demonstrated the important role families play in the weight status of their young children, who depend on them for nourishment, role modeling and setting rules for physical activity and sedentary behaviours. The significant associations of parental weight status as well as home vegetable availability and intake on child weight emphasize the importance of targeting parents to adopt healthful eating behaviours and to prevent becoming obese themselves. The findings also indicated the importance of initiating health interventions at an early age in order to maximize success and prevent future weight gain.

\section{Acknowledgements}

This research was supported by Grant \# 1 R01 HL078846 from the National Institutes of Health, Bethesda, MD, USA. The authors report no conflicts of interest. C.A. conceptualized the project, analysed and interpreted the data, and led the writing and revisions of the manuscript; P.J.H. provided statistical expertise and assisted with the analysis; J.A.F. assisted with analysis and critically edited the manuscript; J.H.H. assisted with interpretation of data and critically edited the manuscript; B.H.R. assisted in data collection and critically reviewed the manuscript; M. Smyth assisted in data collection and critically reviewed the manuscript; and M. Story conceptualized the Bright 
Start study, assisted with interpretation of data and critically edited the manuscript. Thanks are expressed to the many school administrators, teachers and staff, and to the parents on the Pine Ridge Reservation for their interest and support for the Bright Start project to improve the health and development of their children.

\section{References}

1. Ogden CL, Carroll MD \& Flegal KM (2008) High body mass index for age among US children and adolescents, 2003-2006. JAMA 299, 2401-2405.

2. Story M, Stevens J, Himes J et al. (2003) Obesity in American-Indian children: prevalence, consequences, and prevention. Prev Med 37, 6 Pt 2, S3-S12.

3. Zephier E, Himes JH, Story M et al. (2006) Increasing prevalences of overweight and obesity in Northern Plains American Indian children. Arch Pediatr Adolesc Med 160, 34-39.

4. Ogden CL, Flegal KM, Carroll MD et al. (2002) Prevalence and trends in overweight among US children and adolescents, 1999-2000. JAMA 288, 1728-1732.

5. Anderson SE \& Whitaker RC (2009) Prevalence of obesity among US preschool children in different racial and ethnic groups. Arch Pediatr Adolesc Med 163, 344-348.

6. Anderson PM \& Butcher KE (2006) Childhood obesity: trends and potential causes. Future Child 16, 19-45.

7. Olstad DL \& McCargar L (2009) Prevention of overweight and obesity in children under the age of 6 years. Appl Physiol Nutr Metab 34, 551-570.

8. Gallaway MS, Jago R, Baranowski T et al. (2007) Psychosocial and demographic predictors of fruit, juice and vegetable consumption among 11-14-year-old Boy Scouts. Public Health Nutr 10, 1508-1514.

9. Mercille G, Receveur O \& Macaulay AC (2010) Are snacking patterns associated with risk of overweight among Kahnawake schoolchildren? Public Health Nutr 13, 163-171.

10. Huh SY, Rifas-Shiman SL, Rich-Edwards JW et al. (2010) Prospective association between milk intake and adiposity in preschool-aged children. J Am Diet Assoc 110, 563-570.

11. Newby PK, Peterson KE, Berkey CS et al. (2004) Beverage consumption is not associated with changes in weight and body mass index among low-income preschool children in North Dakota. J Am Diet Assoc 104, 1086-1094.

12. O'Connor TM, Yang SJ \& Nicklas TA (2006) Beverage intake among preschool children and its effect on weight status. Pediatrics 118, e1010-e1018.

13. Cullen KW, Baranowski T, Klesges LM et al. (2004) Anthropometric, parental, and psychosocial correlates of dietary intake of African-American girls. Obes Res 12, 12 Suppl., 20S-31S.

14. Collison KS, Zaidi MZ, Subhani SN et al. (2010) Sugarsweetened carbonated beverage consumption correlates with BMI, waist circumference, and poor dietary choices in school children. BMC Public Health 10, 234.

15. Boutelle KN, Fulkerson JA, Neumark-Sztainer D et al. (2007) Fast food for family meals: relationships with parent and adolescent food intake, home food availability and weight status. Public Health Nutr 10, 16-23.
16. Thompson OM, Ballew C, Resnicow K et al. (2004) Food purchased away from home as a predictor of change in BMI z-score among girls. Int J Obes Relat Metab Disord $\mathbf{2 8}$, 282-289.

17. Van Der Horst K, Paw MJ, Twisk JW et al. (2007) A brief review on correlates of physical activity and sedentariness in youth. Med Sci Sports Exerc 39, 1241-1250.

18. Sallis JF, Prochaska JJ \& Taylor WC (2000) A review of correlates of physical activity of children and adolescents. Med Sci Sports Exerc 32, 963-975.

19. DeLong AJ, Larson NI, Story M et al. (2008) Factors associated with overweight among urban American Indian adolescents: findings from Project EAT. Ethn Dis 18, 317-323.

20. Gray A \& Smith C (2003) Fitness, dietary intake, and body mass index in urban Native American youth. J Am Diet Assoc 103, 1187-1191.

21. Lohman TG, Roche AF \& Matheson D (1988) Anthropometric Standardization Reference Manual. Champaign, IL: Human Kinetics Books.

22. Kuczmarski RJ, Ogden CL, Guo SS et al. (2002) 2000 CDC Growth Charts for the United States: methods and development. Vital Health Stat 11, issue 246, 1-190.

23. Story M, Sherwood NE, Himes JH et al. (2003) An after-school obesity prevention program for African-American girls: the Minnesota GEMS pilot study. Ethn Dis 13, 1 Suppl. 1, S54-S64.

24. Cullen KW, Himes JH, Baranowski T et al. (2004) Validity and reliability of a behavior-based food coding system for measuring fruit, $100 \%$ fruit juice, vegetable, and sweetened beverage consumption: results from the Girls Health Enrichment Multisite Studies. Prev Med 38, Suppl., S24-S33.

25. Murray DM (1998) Design and Analysis of Group-Randomized Trials. New York: Oxford University Press.

26. Di Noia J, Schinke SP \& Contento IR (2005) Dietary patterns of reservation and non-reservation Native American youths. Ethn Dis 15, 705-712.

27. Downs SM, Arnold A, Marshall D et al. (2009) Associations among the food environment, diet quality and weight status in Cree children in Quebec. Public Health Nutr 12, 1504-1511.

28. Berkey CS, Rockett HR, Willett WC et al. (2005) Milk, dairy fat, dietary calcium, and weight gain: a longitudinal study of adolescents. Arch Pediatr Adolesc Med 159, 543-550.

29. Story M, Strauss KF, Zephier E et al. (1998) Nutritional concerns in American Indian and Alaska Native children: transitions and future directions. J Am Diet Assoc 98, 170-176.

30. Jollie-Trottier T, Holm JE \& McDonald JD (2009) Correlates of overweight and obesity in American Indian children. J Pediatr Psychol 34, 245-253.

31. Saelens BE, Sallis JF, Nader PR et al. (2002) Home environmental influences on children's television watching from early to middle childhood. J Dev Behav Pediatr 23, 127-132.

32. Adams AK, Harvey H \& Brown D (2008) Constructs of health and environment inform child obesity prevention in American Indian communities. Obesity (Silver Spring) 16, 311-317.

33. Whitaker RC, Wright JA, Pepe MS et al. (1997) Predicting obesity in young adulthood from childhood and parental obesity. N Engl J Med 337, 869-873.

34. Whitaker RC (2004) Predicting preschooler obesity at birth: the role of maternal obesity in early pregnancy. Pediatrics 114, e29-e36. 


\section{Appendix}

\section{Foods and beverages included in the bome} availability and consumption questions

The following food and beverage items were included in the home food availability questionnaire (response categories were 'yes' or 'no').

- Vegetables: corn, peas, lettuce, carrots, tomatoes, green beans, broccoli, courgettes and other squash, French fries or fried potatoes, other vegetables.

- Fruits: apples or apple sauce, bananas, oranges, peaches, pears, fruit cocktail, raisins, other fruits.

- Beverages: 100\% fruit juice; fruit drinks (like Snapple, Hi-C, Sunny D, Bug Juice, fruit punch); regular pop; diet pop; bottled water; Kool-Aid with sugar; energy drinks (like Red Bull, Boo Koo); sports drinks (like Powerade, Gatorade); whole milk; $2 \%$ milk; $1 \%$ or skimmed milk; chocolate milk.

- Salty snacks: potato chips (corn chips, tortilla chips and Cheetos - regular, not baked); pretzels; sunflower seeds.

- Sweet snacks: cakes, cookies, pies; ice cream; doughnuts, sweet rolls, Pop-tarts, muffins; packaged snack cakes (like Ding Dongs, Little Debbie's, etc.); candy.

- Meats and other high-fat foods: bacon or sausage; lunch meat (like bologna); canned meat (like Spam, hash); fried chicken; dried meat; fry bread; butter or margarine; pizza; Ramen noodles.

The following food and beverage items were included in the child food consumption questionnaire (response categories were 'never', '1-3 times last month', '1-2 times a week', '3-4 times a week', '5-6 times a week', 'once a day' and 'more than once a day').

- Beverages: $100 \%$ fruit juice (like orange, apple, grape); fruit drinks (like Snapple, Hi-C, Sunny D, Bug Juice, fruit punch); energy drinks (like Red Bull, Boo Koo); sports drinks (like Powerade, Gatorade); Kool-Aid with sugar; regular pop; diet pop; $1 \%$ or skimmed milk; whole or $2 \%$ milk; chocolate milk; tap water; bottled water.

- Foods: fruit (any kind of fresh, dried, canned or frozen fruit); French fries or fried potatoes; other vegetables (any kind of fresh, dried, canned or frozen vegetables); lettuce salad; cake, cookies, pies; pizza; potato chips, corn chips, tortilla chips, Cheetos (regular, not baked); pretzels; fry bread; sunflower seeds; ice cream; butter or margarine; fried chicken; doughnuts, sweet rolls, Pop-tarts, muffins; candy; food from a fast-food restaurant; hot foods or ready-made foods from a convenience store or gas station. 